\title{
Bacteriological Profile of Chronic Rhino Sinusitis
}

\author{
V.A. Vipula ${ }^{1}$, Fatima Amatullah ${ }^{2}$, Shobha Paul $^{1}$ and B. Lakshmi ${ }^{1}$ \\ ${ }^{1}$ Department of Microbiology, MNR Medical College and Hospital, \\ Sangareddy, Telangana, India \\ ${ }^{2}$ Department of Micribiology, Maheswhwara Medical College \& Hospital, Telangana, Inidia \\ *Corresponding author
}

\section{Keywords}

Rhino sinusitis,

Bacteriology,

Aminoglycosides,

Fluoroquinolones

Article Info

Accepted:

08 June 2018

Available Online:

10 July 2018

A B S T R A C T

Aim of the study is to prospectively examine the Bacteriology of Chronic Rhinosinusitis at MNR Medical College \& Hospital, Sangareddy, and to evaluate the antibiotic sensitivity pattern, and to discuss an empirical basis for the initial choice of the appropriate antibiotic. 217 suspected patients were included in the study. The relevant clinical details of the patients including the co-morbidities in the medical records were examined. Samples like nasal swabs collected during nasal endoscopy under sterile conditions, sinus washings, allergic mucin, tissue biopsy from polyps and tissue biopsy taken from sinus mucosa during nasal surgery, were processed and examined by Microbiology culture using recommended techniques. The antibiotic susceptibility testing was done. Out of 217 patients studied, 131 patients had positive bacterial isolates. Among the isolates Staphylococcus aureus were 32 in number which was the highest followed by Coagulase negative Staphylococci which were 25 in number. Among 131 bacterial isolates, 63 were Gram positive cocci, and were sensitive to most of the common antibiotics like aminoglycosides, amoxicillin, 2nd and 3rd generation cephalosporins. 68 were Gram negative bacilli, and the antibiotic sensitivity was more for amoxicillin, 2nd and 3rd generation cephalosporins and fluoroquinolones. Antibiotic resistance for the common isolates found in CRS ranged from 0-50\%. Bacteriological profile of Chronic Rhinosinusitis at MNR Medical College, Sangareddy was thus evaluated. Hence, it is suggested that culture directed therapy is the gold standard for the management of CRS. If empirical antimicrobial therapy is used to treat CRS, it should be directed against

\section{Introduction}

Chronic rhinosinusitis (CRS), defined as infection of the sinuses lasting for more than 3 months, is one of the most prevalent chronic illnesses in India affecting persons of all age groups. It is generally a mild disease. However, it is important to realize that it afflicts a significant percentage of the population, and causes considerable long term morbidity. Many patients with chronic rhinosinus disease are subjected to multiple courses of antibiotics and surgeries, with little or no improvement in their condition. Despite the tremendous advances in medicine over the last few decades, there have been relatively few advances in the diagnosis and treatment of chronic sinus disease. Long-term results of medical and surgical therapies have resulted in cure rates that vary between 29 and $80 \%{ }^{1,2,3}$. 
We feel that this lack of progress is largely due to the paucity of knowledge on the microbiology and histopathology of chronic sinus disease available to us, and this was the impetus for our study. Rhinosinusitis occurs in both acute \& chronic forms, and represents a potential heterogeneity of pathophysiologies and prognosis. Chronic Rhinosinusitis accounts for more than $90 \%$ of all cases of Rhinosinusitis, has a slow protracted course, and has different etiologies, bacterial and fungal infections being a major cause (Lucknow). The increasing bacterial resistance in acute Rhinosinusitis has been well described, but its prevalence and importance in CRS is not well understood and requires more investigation. A deeper understanding is thus critical, for Otolaryngorhinologists to move from an empiric decision making process, to a more evidence-based or culturedirected therapy paradigm. Hence, a detailed clinical examination, correlation with culture results and a study of the pattern of Antibiotic sensitivity of the isolates becomes necessary in deciding the treatment protocol, and preventing multiple surgical procedures.

We undertook this study to prospectively examine the bacteriology of chronic rhinosinusitis, to evaluate the antibiotic sensitivity pattern, and to discuss an empirical basis for the initial choice of the appropriate antibiotic.

The aims and objectives of the study was:

1. To study the spectrum of Bacterial etiological agents among patients clinically diagnosed as Chronic rhinosinusitis and attending the ENT Outpatient Department MNR Medical College and Hospital Sangareddy, by:

a) Subjecting specimens collected from these patients to microscopy and to bacterial culture. b) Identifying the organism isolated using a battery of biochemical reactions.
2. To study the predisposing factors associated with the range of etiological agents isolated in culture.

3. To determine the antibiogram of the bacteria isolated.

4. To determine the use of antibiotics in the treatment of CRS in patients attending the OPD in ENT Dept. at MNR Medical College \& Hospital, Sangareddy.

\section{Inclusion criteria}

a) All patients with chronic rhinosinusitis diagnosed on the basis of clinical and radiological findings.

b) Allergic rhinitis patients with chronic sinusitis with no response to medical treatment.

c) Patients above 10 years of age, both males and females were included.

\section{Exclusion criteria}

The patients with acute sinusitis, malignancy of paranasal sinuses and patients on recent antibiotics were excluded from study.

\section{Materials and Methods}

This study was conducted at MNR Medical College and Hospital, Sangareddy, Medak Dist., for a period of one year and eight months from November 2011 to August 2013. Specimen processing was done in the Department of Microbiology, MNR Medical College and Hospital, Sangareddy.

A total of 217 specimens were collected from patients suffering from Chronic rhinosinusitis attending the ENT Out patient department of MNR Hospital Sangareddy from 1-11-2011 to 1-08-2013. The relevant clinical details of the patients including the co-morbidities in the 
medical records were examined. These patients underwent a rigid nasal endoscopy with swabs and biopsies from the middle meatus to assess bacterial etiology. CT scans of the paranasal sinus were performed to look for bone erosion and heterogeneous soft tissue opacity if any. Majority of these patients were not responding to conservative line of management with antibiotics.

\section{Specimens included}

Nasal swabs collected during nasal endoscopy under sterile conditions, sinus washings, allergic mucin, collected during nasal resection, tissue biopsy from polyps $\&$ tissue biopsy taken from sinus mucosa during nasal surgery.

\section{Lab methods for isolation and identification of bacteria}

\section{Macroscopic examination}

Samples were inspected for colour, odour and whether they were purulent, blood stained (during surgery), muco purulent, mucoid or clear.

\section{Microscopic examination}

A direct smear of every specimen was made, heat fixed, and stained by Gram's staining technique.

\section{Culture methods used}

The bacterial samples were inoculated with a calibrated loop onto the following media: 5\% sheep's blood agar, chocolate agar and MacConkey's agar plates for culture of aerobic and facultative anaerobic organisms.

The plates were incubated at $37{ }^{\circ} \mathrm{C}$ and were examined after 24 and $48 \mathrm{~h}$. Blood agar and Chocolate agar plates were incubated in an atmosphere of $5-10 \% \quad \mathrm{CO}_{2}$. After overnight incubation, the plates were checked for bacterial growth and colony characters of the isolated bacteria were noted.

With the help of a hand lens, the size, surface and shape of the colonies were noted. The different types of similar looking colonies were marked out on the plate, and each type of colony was picked up with a straight wire and sub cultured into $5 \mathrm{ml}$ of peptone water, to study the biochemical characters and sensitivity pattern. After 6 hrs, a smear was made from the sub culture, stained by Gram's stain and examined for purity of growth. Each type of colony was also picked up for preliminary tests: Hanging drop, Gram's stain, oxidase test and catalase test. A set of sugars were inoculated. The organisms were further identified by using characteristic Bio-chemical reactions for different organisms.

\section{Anaerobic culture methods were not done due to lack of availability of material}

\section{Antibiotic sensitivity testing}

Antibiotic sensitivity was done by using standard "disc diffusion method" (Modified Kirby- Bauer method) on Mueller -Hinton agar plates of $\mathrm{pH}$ value 7.2- 7.4. The bacteria identified as aerobic were submitted to susceptibility tests (disc diffusion test as per the National Committee for Clinical Laboratory Standards (NCCLS) recommendations. The inoculation was standardized according to the standard turbidity degree number 0.5 from the McFarland scale (NCCLS). Interpretation as to susceptibility or resistance to antibiotics was done according to the tables provided by the manufacturer and NCCLS. The antibiotics used in this test were: Ampicillin, Amoxycillin, Methycillin, Amoxyclav, Piperacillin, Cephalexin, Cefaclor, Cefotaxime, Ceftazidime, Cefipime, Imipenem, Vancomycin, Gentamycin, Amikacin, Erythromycin, Azithromycin, Linezolid, Ciprofloxacin, Levofloxacin, 
Cotrimoxazole and Tigecycline.

The reference strain used for antibiotic quality control was Staphylococcus aureus (ATCC 25923) from the American Type Culture Collection (ATCC), according to the recommendations of the National Committee for Clinical Laboratory Standards.

\section{Results and Discussion}

Table 1 shows age incidence and culture positivity. The maximum bacterial culture positivity $(68.51 \%)$ was seen in the age group $31-40$ years

Out of the 217 patients, included in our study, $121(55.76 \%)$ were males with $61.15 \%$ bacterial culture positivity. And 96(44.23\%) were females, with $59.37 \%$ showing bacterial culture positivity as shown in Table 2 .

Out of 217 patients, $158(72.81 \%)$ were from Rural region, 59(27.18\%) were from Urban region. Out of 158 patients from rural region, 93 were culture +ve and out of 59 patients from Urban region, 38 were culture +ve as shown in Table 3.

Among 46 patients, who had nasal allergy, bacterial growth was seen in 26 patients, Among 18 patients, with Diabetes mellitus, bacterial growth was seen in 11 patients, Among 41 patients with dental caries, 24 had bacterial growth 37 smokers 25 were positive for bacteria, and among 6 swimmers 5 had +ve bacterial growth as shown in Table 4 .

The most common symptom was nasal discharge in $76.03 \%$ with $73.33 \%$ bacterial culture positivity. In patients with nasal block $61.29 \%$ were positive for bacteria. Among patients with head ache $65.78 \%$ had bacterial growth. In patients with foul smelling breath $72.72 \%$ had bacterial growth as shown in Table 5. Among 116 patients, with deviated nasal septum, out of 217, positive bacterial cultures were seen in 69 patients,. Among 5 patients, with polyp, 3 patients had positive bacterial growth. And among 138 patients with hypertrophied turbinate, 82 were positive for bacteria as shown in Table 6 .

Out of all the 131 samples that showed bacterial isolates in culture, Staphylococcus aureus was the most common organism isolated, seen in 32 out of 217 specimens (14.74\%). The other bacteria were Coagulase negative Staphylococcus which was isolated in $25(11.52 \%)$ out of 217 specimens, Escherichia coli was isolated in 14 (6.45\%) specimens, Klebsiella pneumoniae in 10 (4.60\%), Klebsiella rhinoscleromatis in $11(5.06 \%)$, Klebsiella oxytoca in $2(0.92 \%)$, Streptococcus pneumoniae in 6(2.76\%), Citrobacter species was isolated in $8(3.68 \%)$, Enterobacter species in $2(0.92 \%)$ specimens, Proteus mirabilis in $8(3.68 \%)$, Proteus vulgaris $5(2.30 \%)$ and Pseudomonas aeruginosa was isolated in 8 (3.68\%) specimens as shown in Table 7.

Among 217 specimens, nasal swabs collected during endoscopy were 102 with 81 showing bacterial. Among 87 sinus washings samples 43 were positive for bacteria Among the 14 tissue biopsies collected from sinus mucosa, bacterial growth was nil. Among the 5 polyps 2 had bacterial growth. This is shown in Table 8.

Number of bacterial positive cultures in Type II Diabetes mellitus cases is shown in Table 9. Among 18 cases of DM, Staphylococcus aureus was isolated in 4(22.22\%) cases, Klebsiella pneumoniae in 2 cases $(11.11 \%)$, CONS, Streptococcus pneumoniae and Proteus mirabilis were isolated in $1(5.55 \%)$ case each, Citrobacter species in $1(5.55 \%)$ case and Pseudomonas aeruginosa was isolated in $1(5.55 \%)$ case. 
Table.1 Age incidence and culture positivity

\begin{tabular}{|c|c|c|c|c|}
\hline Age in years & $\begin{array}{l}\text { No.of cases } \\
\text { tested }\end{array}$ & $\%$ & $\begin{array}{l}\text { Bacterial culture } \\
+\mathrm{ve}\end{array}$ & $\%$ \\
\hline 0-10 & - & - & - & - \\
\hline $11-20$ & 27 & 12.44 & 15 & 55.55 \\
\hline $21-30$ & 56 & 25.80 & 31 & 55.35 \\
\hline $31-40$ & 54 & 18.43 & 37 & 68.51 \\
\hline $41-50$ & 37 & 17.05 & 22 & 59.45 \\
\hline $51-60$ & 20 & 9.25 & 12 & 60 \\
\hline Above 60 & 23 & 10.59 & 14 & 60.86 \\
\hline
\end{tabular}

Chi-Square Value $=16.681$ DF= 5 P-Value $=0.005$

There is Significant association among the age group.

Table.2 Gender incidence and culture positivity

\begin{tabular}{|l|l|l|l|l|}
\hline SEX & NO.TESTED & $\%$ & $\begin{array}{l}\text { Bacterial culture } \\
\text { +ve No. }\end{array}$ & $\%$ \\
\hline MALE & 121 & 55.76 & 74 & 61.15 \\
\hline FEMALE & 96 & 44.23 & 57 & 59.37 \\
\hline
\end{tabular}

Male female ratio: 1.3:1

Table.3 Rural/urban - culture positivity

\begin{tabular}{|l|l|l|l|}
\hline Residential status & No.tested & Bacterial Culture +ve & $\%$ \\
\hline Rural & 158 & 93 & 58.86 \\
\hline Urban & 59 & 38 & 64.40 \\
\hline
\end{tabular}

Table.4 Predisposing factors- culture positivity

\begin{tabular}{|l|l|l|l|}
\hline $\begin{array}{l}\text { PREDISPOSING } \\
\text { FACTOR }\end{array}$ & TOTAL & $\begin{array}{l}\text { BACTERIAL } \\
\text { ISOLATE }\end{array}$ & $\%$ \\
\hline Nasal allergy & 46 & 26 & $56.52 \%$ \\
\hline Dental caries & 41 & 24 & $58.53 \%$ \\
\hline Smoking & 37 & 25 & $62.50 \%$ \\
\hline DM & 18 & 11 & $61.11 \%$ \\
\hline Swimming & 6 & 5 & $83.33 \%$ \\
\hline
\end{tabular}

Table.5 Symptoms-culture positivity

\begin{tabular}{|c|c|c|c|}
\hline $\begin{array}{c}\text { Clinical } \\
\text { presentation } \\
\text { (symptom) }\end{array}$ & Total No. & $\begin{array}{c}\text { Bacterial } \\
\text { culture +ve }\end{array}$ & $\%$ \\
\hline Nasal discharge & 165 & 121 & 73.33 \\
\hline Nasal block & 124 & 76 & 61.29 \\
\hline Head ache & 114 & 75 & 65.78 \\
\hline Foul smell & 44 & 32 & 72.72 \\
\hline
\end{tabular}


Table.6 Clinical finding - culture positivity

\begin{tabular}{|l|l|l|l|}
\hline NASAL OBSTRUCTION & TOTAL & $\begin{array}{l}\text { BACTERIAL } \\
\text { CULTURE } \\
\text { +VE }\end{array}$ & $\%$ \\
\hline POLYP & 5 & 3 & $60 \%$ \\
\hline DNS & 116 & 69 & $59.48 \%$ \\
\hline $\begin{array}{l}\text { TURBINATE } \\
\text { HYPERTROPHY }\end{array}$ & 138 & 82 & $59.42 \%$ \\
\hline
\end{tabular}

Chi-Square Value $=88.62$ DF=2 P-Value $=0.000$

There is Significant Accosiation of Clinical finding

Table.7 Bacterial isolates from 217 cases of CRS

\begin{tabular}{|l|l|l|}
\hline BACTERIAL ISOLATE & No. & $\%$ \\
\hline Staphylococcus aureus & 32 & $14.74 \%$ \\
\hline Coagulase negative Staphylococci & 25 & $11.52 \%$ \\
\hline Streptococcus pneumoniae & 6 & $2.76 \%$ \\
\hline Escherichia coli & 14 & $6.45 \%$ \\
\hline Klebsiella oxytoca & 2 & $0.92 \%$ \\
\hline Klebsiella pneumonia & 10 & $4.60 \%$ \\
\hline Klebsiella rhinoscleromatis & 11 & $5.06 \%$ \\
\hline Citrobacter spp & 8 & $3.68 \%$ \\
\hline Enterobacter spp & 2 & $0.92 \%$ \\
\hline Proteus mirabilis & 8 & $3.68 \%$ \\
\hline Proteus vulgaris & 5 & $2.30 \%$ \\
\hline Pseudomonas aeruginosa & 8 & $3.68 \%$ \\
\hline
\end{tabular}

Table.8 Specimens with culture positivity

\begin{tabular}{|l|l|l|l|}
\hline SPECIMEN & TOTAL & \multicolumn{2}{|l|}{ BACTERIAL } \\
ISOLATES
\end{tabular}

Chi-Square Value $=168.02$ DF=5 P-Value $=0.000$

There is significance between Specimens and culture Positivity

Table.9 Type II DM with bacterial culture positivity

\begin{tabular}{|l|l|l|}
\hline Staphylococcus aureus & 4 & $22.22 \%$ \\
\hline CONS & 1 & $5.55 \%$ \\
\hline Streptoccus pneumoniae & 1 & $5.55 \%$ \\
\hline Klebsiella pneumoniae & 2 & $11.11 \%$ \\
\hline Citrobacter spp & 1 & $5.55 \%$ \\
\hline Proteus mirabilis & 1 & $5.55 \%$ \\
\hline Pseudomonas aeruginosa & 1 & $5.55 \%$ \\
\hline
\end{tabular}


Table.10 Antibiogram of Gram +ve bacteria isolated in our study

\begin{tabular}{|c|c|c|c|c|}
\hline \multirow[t]{2}{*}{ S.NO } & \multirow[t]{2}{*}{ ANTIBIOTIC } & \multicolumn{3}{|c|}{ NO. \& \% OF ISOLATES SENSITIVE: } \\
\hline & & $\begin{array}{l}\text { Staph aureus } \\
\mathrm{N}=32\end{array}$ & $\begin{array}{l}\text { CONS } \\
\mathrm{N}=25\end{array}$ & $\begin{array}{l}\text { Strep pneumoniae } \\
\mathrm{N}=6\end{array}$ \\
\hline 1. & Ampicillin & $27(84.37 \%)$ & $22(88 \%)$ & $6(100 \%)$ \\
\hline 2. & Amoxycillin & $25(78.12 \%)$ & $25(100 \%)$ & $6(100 \%)$ \\
\hline 3. & Amoxyclav & $28(87.5 \%)$ & $25(100 \%)$ & $6(100 \%)$ \\
\hline 4. & Methicillin & $25(78.12 \%)$ & $25(100 \%)$ & $6(100 \%)$ \\
\hline 5 & Piperacillin & $23(71.87 \%)$ & $22(88 \%)$ & $5(83.3 \%)$ \\
\hline 6. & Cephalexin & $20(62.5 \%)$ & $20(80 \%)$ & $4(66.6 \%)$ \\
\hline 7. & Cefaclor & $20(62.5 \%)$ & $22(88 \%)$ & $4(66.6 \%)$ \\
\hline 8. & Cefotaxime & $25(78.12 \%)$ & $24(96 \%)$ & $4(66.6 \%)$ \\
\hline 9. & Ceftazidime & $28(87.5 \%)$ & $20(80 \%)$ & $6(100 \%)$ \\
\hline 10. & Cefipime & $27(84.37 \%)$ & $24(96 \%)$ & $6(100 \%)$ \\
\hline 11. & Imipenem & $24(75 \%)$ & $20(80 \%)$ & - \\
\hline 12. & Vancomycin & $32(100 \%)$ & $25(100 \%)$ & $6(100 \%)$ \\
\hline 13. & Gentamycin & $32(100 \%)$ & $23(92 \%)$ & $2(33.3 \%)$ \\
\hline 14. & Amikacin & $30(93.7 \%)$ & $25(100 \%)$ & $2(33.3 \%)$ \\
\hline 15. & Erythromycin & $28(87.5 \%)$ & $15(60 \%)$ & $3(50 \%)$ \\
\hline 16. & Azithromycin & - & - & - \\
\hline 17. & Linezolid & $32(100 \%)$ & $22(88 \%)$ & $5(83.3 \%)$ \\
\hline 18. & Levofloxacin & $28(87.5 \%)$ & $23(92 \%)$ & - \\
\hline 19. & Cotrimoxazole & $16(50 \%)$ & $18(72 \%)$ & $5(83.3 \%)$ \\
\hline 20. & Tigecycline & $32(100 \%)$ & $20(80 \%)$ & $5(83.3 \%)$ \\
\hline
\end{tabular}

Table.11 Antibiogram of Gram -ve bacteria isolated in our study

\begin{tabular}{|c|c|c|c|c|c|c|c|c|c|c|}
\hline & \multirow[b]{2}{*}{ Antibiotic } & \multicolumn{8}{|c|}{ No.\& \% of isolates sensitive: } & \multirow[b]{2}{*}{$\begin{array}{l}\text { Pseudomon } \\
\text { as } \\
\mathrm{N}=8\end{array}$} \\
\hline & & $\begin{array}{l}\text { E.coli } \\
\mathrm{N}=14\end{array}$ & $\begin{array}{l}K . \\
\text { pneumonia } \\
e \\
\mathrm{~N}=10\end{array}$ & $\begin{array}{l}\text { K. } \\
\text { oxytoca } \\
\mathrm{N}=2\end{array}$ & $\begin{array}{l}\text { K.rhi } \\
\mathrm{N}=11\end{array}$ & $\begin{array}{l}\text { Enterob } \\
\text { acter } \text { spp } \\
\mathrm{N}=2\end{array}$ & $\begin{array}{l}\text { Citro } \\
\mathrm{N}=8\end{array}$ & $\begin{array}{l}P . \\
\text { mirabilis } \\
\mathrm{N}=8\end{array}$ & $\begin{array}{l}P . \\
\text { vulgaris } \\
\mathrm{N}=5\end{array}$ & \\
\hline 1. & Ampicillin & $10(71.42)$ & $6(60)$ & $2(100)$ & $10(90.9)$ & $2(100)$ & $6(75)$ & $6(75)$ & $4(80)$ & - \\
\hline 2. & Amoxycillin & $9(64.28)$ & $4(40)$ & $1(50)$ & $11(100)$ & $2(100)$ & $6(75)$ & $4(50)$ & $3(60)$ & - \\
\hline 3. & Amoxyclav & $10(71.42)$ & $8(80)$ & $2(100)$ & $11(100)$ & $2(100)$ & $8(100)$ & $6(75)$ & $4(80)$ & - \\
\hline 4. & Methycillin & - & - & - & - & $2(100)$ & $8(100)$ & - & - & - \\
\hline 5. & Piperacillin & $7(50)$ & $6(60)$ & $1(50)$ & $8(72.72)$ & $2(100)$ & $6(75)$ & $5(62.5)$ & $3(60)$ & $4(50)$ \\
\hline 6. & $\begin{array}{l}\text { Piperacillin/ } \\
\text { Tazobactam }\end{array}$ & $12(85.7)$ & $8(80)$ & $2(100)$ & $7(63.63)$ & $2(100)$ & $8(100)$ & $6(75)$ & $4(80)$ & $7(87.5)$ \\
\hline 7. & Cephalexin & $11(78.5)$ & $6(60)$ & $2(100)$ & $11(100)$ & $1(50)$ & $6(75)$ & $8(100)$ & $3(60)$ & $7(87.5)$ \\
\hline 8. & Cefaclor & 11(78.5) & $6(60)$ & $1(50)$ & 10(90.9) & $1(50)$ & $6(75)$ & $8(100)$ & $3(60)$ & $7(87.5)$ \\
\hline 9. & Cefotaxime & $12(85.7)$ & $8(80)$ & $1(50)$ & $8(72.72)$ & $1(50)$ & $8(100)$ & $8(100)$ & $4(80)$ & $7(87.5)$ \\
\hline 10. & Ceftazidime & $12(85.7)$ & $10(100)$ & $2(100)$ & $8(72.72)$ & $2(100)$ & $4(50)$ & $8(100)$ & $4(80)$ & $8(100)$ \\
\hline 11. & Cefipime & $12(85.7)$ & $10(100)$ & $2(100)$ & $9(100)$ & $2(100)$ & $8(100)$ & $8(100)$ & $5(100)$ & $8(100)$ \\
\hline 12. & Imipenem & $14(100)$ & $6(60)$ & $2(100)$ & $4(36.36)$ & $2(100)$ & $8(100)$ & $8(100)$ & $3(60)$ & $7(87.5)$ \\
\hline 13. & Vancomycin & - & - & - & - & - & $8(100)$ & - & - & \\
\hline 14. & Gentamycin & $10(71.42)$ & $6(60)$ & $2(100)$ & $8(72.72)$ & $2(100)$ & $8(100)$ & $7(87.5)$ & $3(60)$ & $6(75)$ \\
\hline 15. & Amikacin & $12(85.7)$ & $8(80)$ & $2(100)$ & $7(63.63)$ & $2(100)$ & $8(100)$ & $6(75)$ & $4(80)$ & $5(62.5)$ \\
\hline 16. & Erythromycin & - & - & - & - & $2(100)$ & $8(100)$ & - & $4(80)$ & $7(87.5)$ \\
\hline 17. & Azithromycin & $10(71.42)$ & $6(60)$ & $1(50)$ & $6(54.54)$ & - & - & $6(75)$ & - & - \\
\hline 18. & Linezolid & - & - & - & - & $2(100)$ & $6(75)$ & - & - & - \\
\hline 19. & Ciprofloxacin & $13(92.8)$ & $10(100)$ & $1(50)$ & $6(54.54)$ & $2(100)$ & $8(100)$ & $8(100)$ & $4(80)$ & $7(87.5)$ \\
\hline 20. & Levofloxacin & $12(85.7)$ & $6(60)$ & $2(100)$ & $6(54.54)$ & $2(100)$ & $8(100)$ & $7(87.5)$ & $2(40)$ & $6(75)$ \\
\hline 21. & Cotrimoxazole & $11(78.5)$ & $6(60)$ & $2(100)$ & $7(63.63)$ & $2(100)$ & $6(75)$ & $7(87.5)$ & $2(40)$ & - \\
\hline
\end{tabular}


Rhinosinusitis is a common medical problem encountered in patients attending the Department of Otorhinolaryngology. Rhinosinusitis can be acute or chronic, classified according to the duration of symptoms. Acute rhinosinusitis lasts upto 12 weeks with complete resolution of symptoms, whereas the chronic form persists beyond 12 weeks. Patients with acute sinusitis present with fever, head ache, common cold and other complaints relating to oral or nasal infections. In the chronic form, fever may be low grade. Patients may present with nasal stuffiness, nasal discharge (of any character from thin to thick and from clear to purulent), postnasal drip, facial fullness, discomfort, headache, chronic unproductive cough, hyposmia, sore throat, fetid breath, malaise and easy fatigability.

The etiology, pathogenesis and management of CRS have been one of the most controversial topics in Otolaryngology. The literature available regarding this is sparse and difficult to interpret. In the present study an attempt was made to study the predisposing factors, to examine the bacterial and fungal etiology of CRS and to determine the antibiotic sensitivity of bacterial isolates.

217 patients who were clinically diagnosed as Chronic rhinosinusitis, that attended the Department of ENT, MNR Medical college and Hospital Sangareddy, were studied over a period of 1 year and eight months from 1-112011 to $1-8-2013$.

Endoscopic specimens from these patients were subjected to microscopy, bacterial culture, and biochemical reactions required for identification. The specimens examined were nasal swabs collected during nasal endoscopy, sinus washings, allergic mucin collected during nasal resection, tissue biopsy from polyps and tissue biopsy taken from sinus mucosa during nasal surgery. In our study the common age group of CRS was from 20-70 years. High bacterial culture positivity was seen in the age group 3140years $(68.51 \%)$ followed by the above 60 years age group i.e. $60.86 \%$. In our study male population affected were $55.76 \%$ among the 217 patients studied and their culture positivity was $61.15 \%$ for bacterial infections. The female populations affected were $44.23 \%$ with bacterial culture positivity of $59.37 \%$. There is slight male dominance in the incidence of CRS or in the positivity of the cultures in our study, although less significant than the male dominance reported in studies by Prateek et al., ${ }^{4}$ and Shilpa K Gokale et al., ${ }^{5}$.

In the present study the rural population is high i.e 158 out of 217 with $58.86 \%$ of patients being bacterial culture positive. The urban population is 59 with $64.40 \%$ of bacterial positivity. Among all the predisposing factors studied, like nasal allergy, dental caries, diabetes mellitus, smoking and swimming, the most common predisposing factor was found to be nasal allergy $(21.19 \%)$ followed by dental caries $(18.89 \%)$ in our study. The values are similar when compared with the studies done by Shapira (1985), Turner BW et.al for nasal allergy and studies of Melen and colleagues for dental caries. The most common pathological finding in CRS patients is nasal obstruction in our study. Among 217 patients studied, 138 patients had turbinate hypertrophy, 116 patients had deviated nasal septum and 5 patients had nasal polyps. In all three conditions bacterial culture positivity was around 59\%, Itzahk Brook ${ }^{6}$ et al., 1982, Berry 1930 reported nasal obstruction as a cause of CRS in 54.54\% of cases. It correlates with our study where nasal obstruction is present in more than $50 \%$ of cases. This is the commonest pathological predisposing factor described for CRS. 
The common presenting symptom in our study group was nasal discharge with bacterial culture positivity of $73.33 \%$ followed by foul smelling breath with bacterial culture positivity (72.72\%). This is comparable with most of the other studies.

Microbiological studies of chronic sinusitis often show that the infection is polymicrobial. The bacteria that are implicated in the causation of CRS are varied and include a variety of aerobes, facultative aerobes and obligate anaerobes. Among all the 217 patients in our study, aerobic bacterial growth was positive in $60.36 \%$. The bacterial study of antral aspects by different authors yielded culture positivity rate ranging from 54-92\% (Itzhak Brook, 1989 and Erkan et al., 1994). In a study by Panduranga Kamath et al., ${ }^{7}$ the bacterial growth was $51.24 \%$. When compared with these studies, our study showed higher prevalence for bacterial growths. This shows the high prevalence of bacterial infections in our study area. Due to technical limitations anaerobic bacterial culture was not done in our study.

In our study $14.74 \%$ were Staphylococcus aureus and $11.52 \%$ were Coagulase negative Staphylococci among the bacterial isolates. These bacterial culture results were similar to those of previous studies ${ }^{8,9,10,11,12}$. Staphylococcus aureus and Coagulasenegative Staphylococci were the two most common isolates in CRS. Streptococcus pneumoniae were $2.76 \%$ in our study, whereas the incidence is only $1 \%$ in other studies (Panduranga kamath et al., ${ }^{7}$ ). Escherichia coli that were isolated in our study were $6.45 \%$ which correlates with the study of Katriina Kostamo et al., ${ }^{13}$ (7\%). Klebsiella species were $10.59 \%$ in our study group, and the values correlate with most of the other studies like Hashemi et al., ${ }^{14}$, Panduranga Kamath et al., ${ }^{7}$. Citrobacter species, Proteus mirabilis and Pseudomonas aeruginosa were isolated in equal numbers of $3.68 \%$. As per the other reports, these organisms are also associated with the etiology of CRS. Enterobacter species were the least identified in our study i.e. $0.92 \%$ and also correlates with other studies. Proteus species that were isolated were $2.3 \%$. This is slightly less than that of the study of Katriina Kostamo et al., ${ }^{13}(7 \%)$. From all the above observations, the types of bacteria isolated and their incidence in our study, are almost similar to the other studies.

Among the various specimens examined, nasal swabs taken during endoscopy were highest in number. Bacterial isolates were more in throat swabs (100\%) followed by nasal swabs $(79.41 \%)$.

In our study among 217 patients with CRS 18 patients was Diabetics. Bacterial isolates were $61.11 \%$. When compared with other etiological factors, diabetes mellitus as a predisposing factor is less common. The infection rate is more in patients with diabetes mellitus.

The gram positive coccii isolated in our study were 63 in number with Staphylococcus aureus 32, Coagulase negative staphylococci 25 and Streptococcus pneumoniae 6 in number. Around 20 drugs were tested for sensitivity. Staphylococcus aureus were highly sensitive to Vancomycin, Gentamycin, Linezolid and Tigecycline with 100\% sensitivity to each drug. It was $93.7 \%$ sensitive to Amikacin. Methycillin resistant Staphylococcus aureus (MRSA) was detected in 7 patients i.e $3.22 \%$. MRSA isolation in our study is similar to that of the study by Panduranga et al., ${ }^{7}$. Coagulase negative Staphylococci(CONS) were more sensitive to antibiotics like Amoxycillin, Amoxyclav, Methicillin, Vancomycin, Amikacin with $100 \%$ sensitivity to each drug. Sensitivity for Cefataxime and Cefipime was $96 \%$ and for 
Gentamycin and Levofloxacin it was $92 \%$. Streptococcal pneumoniae were less in number, but had similar antibiotic sensitivity pattern like CONS (Table 10 and 11).

Gram negative bacilli isolated in our study were 61 in number. Among them Escherichia coli were 14, Klebsiella species were 16, Citrobacter spp, Proteus spp, Pseudomonas aeruginosa were 8 in each group. Around 21 drugs were tested for sensitivity.

Escherichia coli were mostly sensitive to Imipenem $100 \%$, Ciprofloxacin $92.8 \%$. It was $85.7 \%$ sensitive to the other drugs like Piperacillin, Piperacillin/Tazobactam, Cefotaxime, Ceftazidime, Cefipinem, Amikacin and Levofloxacin.

Klebsiella species were highly sensitive to Ampicillin, Amoxyclav, Ceftazidime, Cefipime, Imipenem, Gentamycin, Amikacin, Levofloxacin, Cotrimoxazole with 100\% sensitivity for each. Sensitivity for other less common gram negative bacilli was also similar.

Beta lactamase producing bacteria were also isolated in our study. The isolates ranged from $11-35 \%$. This numbers are similar to the study of Katriina Kostamo et al., ${ }^{13}$.

Most of the organisms isolated in our study were sensitive to Aminoglycosides, Amoxycillin, 2nd and 3rd generation Cephalosporins. Our findings are similar to the findings of other studies by Shilpa K Gokale et al., ${ }^{5}$ and Hashemi et al., ${ }^{14}$.

Resistance rates of the antibiogram ranged from $0-40 \%$ for common gram positive cocci and $0-50 \%$ for the common gram negative bacilli in our study.

From our study we conclude that the most common predisposing factors for CRS are nasal allergy, dental caries and nasal obstruction. Out of 217 patients studied, 131 patients showed bacterial culture positivity. This shows that most of the CRS are due to bacterial infections. The common bacterial infections are due to Staphylococcus aureus, CONS and Klebsiella species. Most of the bacteria are sensitive to the commonly used antibiotics in general practice like Aminoglycosides, Amoxycillin, 2nd and 3rd generation Cephalosporins. Antibiotic resistance for the common isolates found in CRS ranged from $0-50 \%$.

Hence, it is suggested that culture directed therapy is the gold standard for the management of CRS. If empirical antimicrobial therapy is used to treat CRS, it should be directed against Staphylococcus aureus, CONS and Klebsiella.

\section{References}

1. Hamaguchi, Y., M. Ohi, Y. Sakakura, and Y. Miyoshi. 1986. Significance of lysosomal proteases; cathepsins $\mathrm{B}$ and $\mathrm{H}$ in maxillary mucosa and nasal polyp with non-atopic chronic inflammation. Rhinology 24: 187-194

2. Melen, I., L. Lindahl, and L. Andreasson. 1986. Short and long-term treatment results in chronic maxillary sinusitis. Acta Otolaryngol. (Stockholm) 102: 282-290.

3. Murray, J. P., and M. S. Jackson. 1983. Complications after treatment of chronic maxillary sinus disease with CaldwellLuc procedure. Laryngoscope, 93: 282284.

4. 4.Prateek S, Banerjee G, Gupta P, Singh M, Goel MM, Verma V. Fungal rhinosinusitis: A prospective study in a University hospital of Uttar Pradesh. Indian J Med Microbiol 2013; 31: 266-9.

5. Shilpa K Gokale, Shashidhar S suligavi Bacteriological study of Chronic maxillary sinusitis with special reference to 
anaerobes. Clinical Rhinology :An international. journal, September December 2010 3(3) 141- 144

6. Brook, I. 1981. Bacteriologic features of chronic sinusitis in children. JAMA 246:967-969.

7. M. Panduranga Kamath, Vijendra Shenoy S, Nitin Mittal, nitish Sharma Microbiological analysis of paranasal sinuses in chronic sinusitis- A south Indian coastal study. Egyptian journal of Ear, Nose, Throat and Allied Sciences (2013)14.185,189.

8. Brook I. Bacteriology of chronic maxillary sinusitis in adults. Ann Otol Rhinol Laryngol. 1989; 98: 426-428.

9. Hamilos DL. Chronic sinusitis.J Allergy Clin Immunol. 2000; 106:213-227.

10. Jousimies-Somer HR, Savolainen S, Ylikoski JS. Comparison of the nasal bacterial floras in two groups of healthy subjects and in patients with acute maxillary sinusitis. J Clin Microbiol.
1989;27:2736-2743.

11. Savolainen S, Ylikoski J, JousimiesSomer $\mathrm{H}$. The bacterial flora of the nasal cavity in healthy youngmen. Rhinology. 1986;24:249-255.

12. Wald ER. Microbiology of acute and chronic sinusitis in children and adults. Am J Med Sci.1998;316:13-20.

13. Katriina Kostamo, Malcolm Richardson, Anni Virolainen-Julkunen, Ilmo Leivo, Henrik Malmberg, Jukka Ylikoskil and Elina Toskala1Microbiology of chronic hyperplastic sinusitis. Rhinology, 42, 213218, 2004

14. M. Hashemi MD, M. Mir Mohammad Sadeghi MD, MR. Omrani MD, MA. Torabi MD. Microbiology and antimicrobial resistance in chronic resistant rhino sinusitis with or without polyp after functional endoscopic sinus surgery Chronic Resistant Rhino SinusitisPolyp-Endoscopic Sinus Surgery JRMS 2005; $\quad 10(3)$ :

$167-171$

\section{How to cite this article:}

Vipula, V.A., Fatima Amatullah, Shobha Paul and Lakshmi, B. 2018. Bacteriological Profile of Chronic Rhino Sinusitis. Int.J.Curr.Microbiol.App.Sci. 7(07): 999-1009. doi: https://doi.org/10.20546/ijcmas.2018.707.121 